\title{
An Investigation Into the Knowledge, Attitude and Predictors of Safe Abortion Among Female Students in the Eastern Cape, South Africa
}

Given Mutinta ( $\sim$ Chigaya24@gmail.com )

Nelson Mandela University

\section{Research Article}

Keywords: knowledge, attitude, predictors of abortion, safe abortion, female students, Eastern Cape universities

Posted Date: March 25th, 2022

DOI: https://doi.org/10.21203/rs.3.rs-1345930/v2

License: (c) (1) This work is licensed under a Creative Commons Attribution 4.0 International License.

Read Full License 


\section{Abstract}

\section{Background}

Safe abortions are performed throughout the world. In South Africa, abortion is legal but over half of abortions remain unsafe and there is a dearth of studies on safe abortion among students. The aim of this study was to investigate into the knowledge, attitude, and predictors of safe abortion among female students in the Eastern Cape Province, South Africa.

\section{Methods}

The study was guided by a cross-sectional research design and underpinned by quantitative methodology. A self-administered questionnaires was used to collect data from female students selected using a multi-stage sampling method. Data was analysed using SPSS version 24 , and bivariate and multivariable logistic regression was performed to determine the association of dependent and independent variables.

\section{Results}

Data was collected from 1266 female students with the response rate of more than $100 \%$. The study found that 866 (68.5\%) of the students had good knowledge about safe abortion. Having ever heard about safe abortion $(\mathrm{AOR}=4.37,95 \% \mathrm{Cl}: 1.89,10.84)$, older age $(\mathrm{AOR}=2.79,95 \% \mathrm{Cl}: 1.17,7.29)$, family education ( $\mathrm{AOR}=3.19,95 \% \mathrm{Cl}: 1.33,7.07)$, and urban habitation $(\mathrm{AOR}=2.43,95 \% \mathrm{Cl}: 1.27,4.36)$ were predictors of students' knowledge of safe abortion. Findings show that $722(57 \%)$ of students had favourable attitude towards safe abortion. Staying in an urban area (AOR $=1.52,95 \% \mathrm{Cl}: 1.10,2.22)$, and age (AOR $=6.59,95 \% \mathrm{Cl}: 2.72,11.22)$ were found to be significant predictors of students' attitude towards safe abortion.

\section{Conclusion}

The study revealed that half of the students had good knowledge and attitude towards safe abortion while a significant proportion had poor knowledge and unfavourable attitude. Findings show that having ever heard about abortion, residence, age of students, and family education were predictors of knowledge on safe abortion. In addition, age and residents were predictors of students' attitude towards abortion. There is need for health communication and education programmes to address the subject of safe abortion among students. Health communication and education programmes should target students from rural areas and employ age-specific programmes. Government should provide youth-friendly reproductive services to the rural areas of South Africa.

\section{Plain English Summary}

Safe abortions are performed throughout the world. In South Africa, abortion is legal but over half of abortions remain unsafe and there is a dearth of studies on safe abortion among students. The aim of 
this study was to investigate into the knowledge, attitude, and predictors of safe abortion among female students in the Eastern Cape Province, South Africa.

The study was guided by a cross-sectional research design and underpinned by quantitative methodology. A self-administered questionnaires was used to collect data from female students selected using a multi-stage sampling method. Data was analysed using SPSS version 24. Data was collected from 1266 female students.

The study revealed that half of the students had good knowledge and attitude towards safe abortion while a significant proportion had poor knowledge and unfavourable attitude. Findings show that having ever heard about abortion, residence, age of students, and family education were predictors of knowledge on safe abortion. In addition, age and residents were predictors of students' attitude towards abortion.

In conclusion, there is need for health communication and education programmes to address the subject of safe abortion among students. Government should provide youth-friendly reproductive services to the rural areas of South Africa.

\section{Background}

Abortion is "understood as putting to an end of a foetus in the uterus using surgery or taking medicines 22 . Abortion is carried out because the pregnancy is not desired or there are complications related to the uterus or foetus or other parts of the mother during pregnancy $(22,26)$. Unsafe abortion is therefore is the termination of pregnancy carried out by a person lacking the standardised skills in a place that does not meet minimal medical standards $(22,23)$. Therefore, unsafe abortion includes: the termination of the foetus in the uterus carried out by a personnel who is not trained in unhealthy conditions; those selfinduced by putting in foreign objects into her uterus or consuming deadly products; and those initiated by physical trauma" to a woman's abdomen (22).

Global statistics "show that $45 \%$ of all induced abortions are unsafe (22). Out of all unsafe abortions, one third were performed under the least safe conditions, namely, by untrained persons using dangerous and invasive methods. Developing countries bear the burden of $97 \%$ of all unsafe abortions (22). More than half of all unsafe abortions occur in Asia, most of them in south and central Asia. In Latin American and Africa, the majority, approximately 3 out of 4 of all abortions are unsafe (26). In Africa, nearly half of all abortions occur under" the least safe circumstances (2).

Evidence "shows that unsafe abortion is a leading but preventable cause of maternal deaths and morbidities $(10,27)$. It leads women's physical and mental health complications and social and financial burdens, communities and health" systems. This makes "lack of access to safe, timely, affordable and respectful abortion care a critical public health and human rights issue. In South Africa, abortion is legal since 1996, however over half of abortions are still estimated to be unsafe (8). National maternal death reports, which notably no longer distinguish abortion from spontaneous miscarriage, suggest mortality from 'miscarriage/abortion' surged 62\% between 2002-2004 and 2011-2013 (9). Further, women who 
are of lower socioeconomic status are at higher risk of unsafe abortion and its health consequences than women who are more affluent. Barriers to safe abortion care including fear of discrimination or confidentiality breech, abuse and neglect by health workers, a dearth of abortion providers, waiting lists, gestational limits, long distances, insufficient knowledge about abortion laws and financial constraints ( 1 , $2,5,11)$. Many researchers attribute these barriers to weaknesses of the South African health system generally and to abortion stigma specifically a social process that ascribes negative attributes to women who access abortion care, to abortion providers and to others associated" with abortion $(2,3,6,27)$.

Students "fall within the age category of people at high risk of unsafe abortion, and there is a dearth of published studies on the knowledge, attitude, and predictors of safe abortion among university students in South Africa. Therefore, this study will investigate into the knowledge, attitude, and predictors of safe abortion among female students in the Eastern Cape Province, South Africa. Thus, this study may inform the development of reproductive health guidelines and enhance education and communication health programmes to enhance safe abortions among" students.

\section{Methods}

\section{Research design}

A cross-sectional "research design was used to guide the study among female students in public universities in Eastern Cape Province, South Africa. A cross-sectional research design was used because the design allows studies to collect data to make inferences about a population of interest at one point in time (4). A cross-sectional research design makes snapshots of the populations about which they gather data. Besides, this design was chosen because it allows studies to collect data from many different individuals at a single point in time. In this case, data were collected from four different public universities" in Eastern Cape.

\section{Research approach}

The study used "quantitative research approach which is the process of collecting and analysing numerical data (4). Quantitative research approach can be used to find patterns and averages, make predictions, test causal relationships, and generalise results to wider populations. Quantitative research methodology in this study is used to quantify the knowledge, attitude, and predictors of safe abortion among female students using numerical data that is transformed into statistics. These statistics helped to understand the research problem under study. Quantitative research methodology was also used because many researchers agree that quantitative methodology is the best when it comes to measuring opinions, views, behaviours, attitudes, practices, and other measurable variables (21). Evidence shows that quantitative research methodology is effective in uncovering and formulating facts (4). This study employed quantitative methodology to measure knowledge, attitude, and predictors of safe abortion among female students. The method was also used because it is helpful in conducting structured studies and collecting information that is" generalisable. 


\section{Sampling technique}

The study "used multi-stage sampling method to select respondents. In the first stage, all universities in Eastern Cape namely Nelson Mandela University (NMU), University of Fort Hare (UFH), Rhodes University $(\mathrm{RU})$ and Walter Sisulu University were selected using census sampling technique. Second stage, from each University, faculties and colleges were categorised as faculties/colleges of humanities, agriculture, engineering and science, health sciences and law and management studies. Third stage, the list of female students was generated from students' register in each faculty/college using proportional sampling technique distributed based on female students' level of study. This was followed by the application of simple random sampling technique to select the sample for the study from six thousand female students. One thousand two hundred sixty six (1266) students successfully" completed the questionnaire.

\section{Data collection instruments}

Data were "collected using a questionnaire. To achieve the aim of the study and high response rate, six thousand female students in the first, second, third-and fourth-year level of study were invited to complete the questionnaire through their respective university communication systems. The survey used a questionnaire with several items including demographics, knowledge, and attitude towards safe abortion. The questionnaire was reviewed by" experts in survey research for face validity.

A pilot sample $(n=10)$ was "used to improve the wording and clarity of expression of the survey items. Data from the pilot sample was not used in any further analysis. The final version of the questionnaire required an estimated time of 5-15 minutes to complete. The questionnaire was posted online together with the consent form describing the purpose of the study in detail. One thousand two hundred sixty six questionnaires were collected. The total number of female students expected to complete the survey was 6000 . Using the confidence level $95 \%$, population size 6000 and margin of error $5 \%$ the ideal sample size is 365 but this study generated 1266 questionnaires expressing more than one hundred per cent response rate. It was easy to conduct the study because the researcher was a senior lecturer at one of the universities under study and has expertise in health communication and research methodology studies. The researcher's experience in health communication and research methodology span more than twelve years. All completed questionnaires were checked" for completeness by the investigator.

\section{Variables and measurements}

The "study investigated into the knowledge, attitude, and predictors of safe abortion among female students. Knowledge of students on safe abortion was assessed using eight questions that generated a high internal consistency namely Cronbach's alpha $=0.712$. Each of the correct responses was given one point while zero was given for the incorrect response based on students' responses. Students who scored less than $60 \%$ in the knowledge questions were reported as having poor knowledge and students who scored higher than or equal to $60 \%$ were reported as having good" knowledge. 
Students' attitude "towards safe abortion was calculated out of eleven questions that generated a high internal consistency namely Cronbach's alpha $=0.706$. The study employed a five-point Likert scale: $1=$ strongly disagree; 2 = disagree; 3 = neutral; 4 = agree; and 5 = strongly agree; and then categorised as "agree" (strongly agree and agree) and "disagree" (strongly disagree, disagree, and neutral). All students who scored less than the mean score were reported as having unfavourable attitudes and all students who scored greater than or equal to the mean were reported as possessing favourable attitudes towards safe abortion. Independent variables in the study were sex, age, marital relationship, place of resident, financial support from the family, and year" of study.

\section{Ethical considerations}

With adequate "knowledge of the study, female students were asked to sign the consent form by ticking on the right side of the questionnaire if they wanted to participate. Students were informed that participation in the study was voluntary and were at liberty to withdraw from the study anytime without any consequences. Confidentiality, privacy, and anonymity were upheld. The contact details for Nelson Mandela University Research Office were provided in case students had questions. The four universities under study provided gatekeepers' letters and Nelson Mandela University provided ethical clearance. The questionnaire ran" online from July 2021 to August 2021.

\section{Data analysis}

Data were "analysed using descriptive statistics that included the computing of percentages and frequencies. Bivariate and multivariable logistic regression analyses were performed, and adjusted odds ratios (AORs) calculated with 95\% confidence interval to determine the associations between safe abortion and independent variables. All variables with a $p=$ value $<.25$ in the bivariate analysis were considered for the final multivariable analysis while variables with a $p=$ value $<.05$ were considered in the final multivariable logistic regression model to determine significance of the association with the outcome variable" safe abortion.

\section{Demographic characteristics of the respondents}

The "study involved 1266 respondents with a response rate of more than hundred per cent. The study's average age was 21.8 years ( $S D \pm 2.98)$. Findings indicate that $778(61.5 \%)$ of students were single, and $676(53.4 \%)$ had parents who were both illiterate. The study found that $990(78.3 \%)$ of the students lived in urban areas before they joined the university" as shown in Table 1.

\section{Table 1: Socio-demographics characteristics of students}




\begin{tabular}{lll|}
$\begin{array}{l}\text { Age group } \\
18 \text { years to } 19 \text { years }\end{array}$ & 176 & 11.7 \\
\hline 20 years to 24 years & 820 & 65.9 \\
\hline 25 years & 270 & 22.4 \\
\hline
\end{tabular}

\section{Relationship status}

Never been in a relationship

$778 \quad 61.6$

Not in a relationship at the moment

162

12.9

In a relationship but not married

160

12.7

Married

166

13.2

\section{Family education}

They are both illiterate

676

53.5

One of my parents is literate and the other one illiterate

428

33.9

They are both literate

162

12.9

\section{Area of residence}

$\begin{array}{lll}\text { Urban } & 376 & 21.9 \\ \text { Rural } & 990 & 78.2\end{array}$

\section{University}

Nelson Mandela University

424

33.6

University of Fort Hare

286

22.7

Rhodes University

276

21.9

Walter Sisulu University

280

22.2 


\begin{tabular}{|lcc|}
\hline Year of study & & \\
\hline First year & 286 & 22.7 \\
\hline Second year & 414 & 32.8 \\
\hline Third year and above & 566 & 44.8 \\
\hline Monthly stipend from family & & \\
\hline <R500 & & \\
\hline R501-R1000 & 906 & 71.7 \\
\hline$>$ R1001 & 286 & 22.7 \\
\hline
\end{tabular}

\section{Students' knowledge of safe abortion}

Results show "that 866 (68.5\%) of the students in this study had knowledge on safe abortion. Most of the students $1218(96.3 \%)$ had heard about safe abortion out of which $966(79.4 \%)$ heard about safe abortion from health institutions. Results indicate that $1196(80.4 \%)$ of the students reported unsafe abortion as a major health problem, and 904 (71.5\%) reported that South Africa has laws on abortion. The study found that 630 (49.9\%) of the students reported hospitals as places they knew performing safe abortion. Results indicate that 752 (59.5\%) of all students in the study reported that safe abortion should be carried out up to three months of the pregnancy" as presented in Table 2.

\section{Table 2: Students' knowledge of on safe abortion}




\begin{tabular}{|lll|}
\hline Items & Frequency & Per centage \\
\hline Have you ever come across information on methods of abortion? & \\
\hline Yes & 1218 & 96.3 \\
\hline No & 48 & 3.8 \\
\hline & & \\
\hline What is the source of your information on safe abortion? & \\
\hline Health institution & 966 & 79.4 \\
\hline Mass media & 826 & 67.9 \\
\hline Parents & 432 & 35.6 \\
\hline Other & 84 & 6.9 \\
\hline & & \\
\hline Where are safe abortions performed? & & \\
\hline Health centre & 246 & 22.7 \\
\hline Home & 106 & 8.5 \\
\hline Hospital & 620 & 49.9 \\
\hline Private clinic & 222 & 17.6 \\
\hline
\end{tabular}

\begin{tabular}{|lcc|}
\hline \multicolumn{4}{|c|}{ Can safe abortion services help to reduce reproductive health problem } & women face? \\
\hline Yes & 426 & 33.7 \\
\hline No & 568 & 44.9 \\
\hline I do not know & 272 & 21.6 \\
\hline
\end{tabular}

\begin{tabular}{|l|l|l|}
\hline When is it suitable time to perform safe abortion? & & \\
\hline Any time during pregnancy & 514 & 40.7 \\
\hline Before pregnancy clocks three months & 752 & 59.5
\end{tabular}

Do you think unsafe abortion is a major health issue in South Africa?

$\begin{array}{lrr}\text { Yes } & 1016 & 80.4\end{array}$




\begin{tabular}{|c|c|c|}
\hline No & 250 & 19.8 \\
\hline \multicolumn{3}{|l|}{ Is abortion legal in South Africa? } \\
\hline Yes & 904 & 71.5 \\
\hline No & 362 & 28.7 \\
\hline \multicolumn{3}{|l|}{ What is the reason abortion is legal in South Africa? } \\
\hline If a woman has physical/mental disabilities & 718 & 56.8 \\
\hline If a woman is physically psychologically not ready & 910 & 71.9 \\
\hline If one is not financially able to rise the child & 984 & 77.8 \\
\hline If pregnancy endangers life of the woman or foetus & 528 & 41.8 \\
\hline If pregnancy is due to rape or incest & 652 & 51.5 \\
\hline If the pregnancy is extra-marital & 1032 & 81.6 \\
\hline Not allowed for any reason in South Africa & 408 & 32.3 \\
\hline
\end{tabular}

\section{Students' attitudes towards safe abortion}

The results "indicate that $722(57 \%)$ of students in the study reported a positive attitude towards safe abortion while 1062 (83.9\%) disagreed to the view that elective abortion should be accessible and legal. Most of the students 922 (72.9\%) disagreed to the view on the legalisation of safe and voluntary abortion, 870 (68.8\%) agreed to the statement that abortion services should be available at health institutions, and $812(64.2 \%)$ of the students agreed to the statement that men should play a role in the decision" of abortion as demonstrated in Table 3.

Table 3: Students' attitude towards safe abortion 


\begin{tabular}{|lll|}
\hline Items & Disagree & Agree \\
& $\mathrm{N}(\%)$ & $\mathrm{N}(\%)$ \\
Safe and voluntary abortion should be legal and accessible & 922 & 344 \\
& $(72.8)$ & $(27.3)$ \\
Elective abortion should be legal and accessible under any circumstance & 1062 & 204 \\
& $(83.9)$ & $(16.2)$ \\
A woman under 18 asking for safe abortion service should be allowed & 852 & $514(32.8)$ \\
to have the service & $(67.3)$ & \\
Safe abortion is acceptable if a person has no resources to rise the child & 852 & 404 \\
& $(68.1)$ & $(31.9)$ \\
Safe abortion is acceptable to prevent mother's life or foetal anomaly & 722 & 554 \\
& $(57.0)$ & $(43.1)$ \\
It is acceptable for a woman to choose safe abortion because of rape or & 616 & 650 \\
incest & $(48.7)$ & $(51.4)$ \\
Provision of safe abortion after unwanted pregnancy can save mothers' & 542 & 724 \\
life & $(42.8)$ & $(57.3)$ \\
Males partners have influence in the decision to have an abortion & 454 & 812 \\
Health centres and hospitals should provide safe abortion services & $(35.9)$ & $(64.2)$ \\
A woman has the right to terminate her pregnancy & 396 & 870 \\
Adolescent students use induced abortions to terminate pregnancies & 570 & $(31.3)$ \\
& $58.8)$ \\
\hline
\end{tabular}

Factors affecting students' knowledge towards safe abortion

The 'bivariate analysis found students' marital status, family education, year of study, residence, age, and hearing about abortion to be associated with students' knowledge of safe abortion. The multivariate analysis found residence, family education, age, and hearing about abortion to be associated with students' knowledge" of safe abortion.

Students aged 25 "and above were reported to be 2.79 times more likely to have good knowledge of safe abortion than students aged between 18 and 19 (AOR 2.78, 95\% Cl: 1.17, 7.28). Students from urban areas were 2.42 times more knowledgeable than students from rural areas (AOR 2.43, 95\% Cl: 1.27, 4.36), and students who had heard about safe abortion were 4.36 times more likely to have good knowledge than their counterparts (AOR 4.37, 95\% Cl: 1.89, 10.84). Students living with both parent who were literate were 3.18 times more likely to have good knowledge of safe abortion than their" counterparts (AOR 3.19, $95 \% \mathrm{Cl}: 1.33,7.07)$ as shown in Table 4. 
Table 4: Predictors of students' knowledge of safe abortion 


\begin{tabular}{|c|c|c|c|c|}
\hline \multirow[t]{2}{*}{ Items } & \multicolumn{2}{|c|}{ Knowledge } & \multirow{2}{*}{$\begin{array}{l}\text { COR }(95 \% \\
\text { Cl) }\end{array}$} & \multirow[t]{2}{*}{ AOR $(95 \%$} \\
\hline & Good & Poor & & \\
\hline \multicolumn{5}{|c|}{ Age group } \\
\hline 18 to 19 & 126 & 50 & 1 & 1 \\
\hline 20 to 24 & 572 & 248 & $\begin{array}{l}1.10(0.87, \\
1.49)\end{array}$ & $\begin{array}{l}1.12(0.95, \\
2.37)\end{array}$ \\
\hline$\geq 25$ & 168 & 102 & $\begin{array}{l}1.54(1.07 \\
2.15)\end{array}$ & $\begin{array}{l}2.79 \text { (1.17, } \\
7.29)\end{array}$ \\
\hline
\end{tabular}

\section{Relationship status}

Never been in a relationship

$\begin{array}{llll}548 & 230 & 1 & 1\end{array}$

Not in a relationship at the moment

$122 \quad 40$

$0.79(0.46$ 1.36)

$0.75(0.49$, 1.39)

In a relationship but not married

90

70

$1.86(1.14$, 3.04)

$1.88(0.95$,

Married

106

$\left.\begin{array}{lll}60 & 1.36 \\ 2.23\end{array}\right)\left(\begin{array}{ll}0.83, & 1.69 \\ & \end{array}\right.$

\section{Family education}

Both parents are illiterate

One of my parents is literate and the other one illiterate

Both of my parents are literate

$\begin{array}{llll}443 & 230 & 1 & 1\end{array}$

298

130

$0.86(0.59$, 1.23)

122

40

$1.65(1.11$, 3.28)
1

0.92 (0.69, 1.29)

3.19 (1.33, 7.07)

\section{Residence}

Rural $\begin{array}{llll}684 & 306 & 1 & 1\end{array}$

Urban 182

$94 \quad 1.16(0.78$, 1.73)

1

$2.43(1.27$, 4.36)

\section{Year of study}

First year 
Third year and above

482

86

$0.39(0.25$,

$0.65)$

$1.29(0.83$, 2.04)

Having ever heard about abortion

Yes

848

370

$3.83(1.65$, 8.89)

4.37 (1.89,

No

18

30

1

1

Monthly stipend from family

$<$ R500

$\begin{array}{llll}602 & 304 & 1 & 1\end{array}$

R501-R1000

$206 \quad 80$

$0.72(0.52$, 1.17)

$0.94(0.43$,

$>$ R1001

58

16

$0.62(0.25$, $1.23)$

\section{Factors affecting students' attitude towards safe abortion}

Findings in the "bivariate analysis show that marital status, family education, age, religion and residence were associated with students' attitude towards safe abortion. The multivariate logistic regression included all explanatory variables that were considered in the bivariate analyses. Results show that students' place of residence and age remained significantly associated with students' attitude of safe abortion. Results indicate that students coming from urban residents were 1.51 more likely to have a favourable attitude of safe abortion than their counterparts (AOR 1.52, 95\% Cl: 1.09, 2.22), and students aged between 25 and above were 6.58 times more likely to have a favourable attitude of safe abortion than students" aged between 18-19 (AOR 6.59, 95\% Cl: 2.72, 11.22) as presented in Table 5.

Table 5: Predictors of students' attitude towards safe abortion 


\begin{tabular}{|c|c|c|c|c|}
\hline \multirow[t]{2}{*}{ Items } & \multicolumn{2}{|l|}{ Attitude } & \multirow[t]{2}{*}{ COR (95\% Cl) } & \multirow[t]{2}{*}{ AOR $(95 \% \mathrm{Cl})$} \\
\hline & Favourable & Unfavourable & & \\
\hline \multicolumn{5}{|l|}{ Age } \\
\hline 18 to 19 & 156 & 20 & 1 & 1 \\
\hline 20 to 24 & 438 & 382 & $\begin{array}{l}6.81(1.44 \\
10.48)\end{array}$ & $\begin{array}{l}4.69(0.97 \\
9.85)\end{array}$ \\
\hline$>25$ & 128 & 142 & $\begin{array}{l}8.66(2.14, \\
12.46)\end{array}$ & $\begin{array}{l}6.59(2.72 \\
11.22)\end{array}$ \\
\hline \multicolumn{5}{|l|}{ Relationship status } \\
\hline Never been in a relationship & 396 & 382 & 1 & 1 \\
\hline $\begin{array}{l}\text { Not in a relationship at the } \\
\text { moment }\end{array}$ & 126 & 36 & $\begin{array}{l}0.29(0.18 \\
1.04)\end{array}$ & $\begin{array}{l}2.49(0.75 \\
4.31)\end{array}$ \\
\hline In a relationship but not married & 88 & 72 & $\begin{array}{l}0.86(0.53 \\
1.39)\end{array}$ & $\begin{array}{l}0.79(0.38 \\
1.65)\end{array}$ \\
\hline Married & 112 & 54 & $\begin{array}{l}0.51(0.32 \\
0.83)\end{array}$ & $\begin{array}{l}1.59(0.82 \\
3.15)\end{array}$ \\
\hline \multicolumn{5}{|l|}{ Family education } \\
\hline Both illiterate & 368 & 308 & 1 & 1 \\
\hline One literate, one illiterate & 252 & 176 & $\begin{array}{l}0.84(0.59 \\
1.19)\end{array}$ & $\begin{array}{l}0.95(0.56, \\
1.62)\end{array}$ \\
\hline Both parents are literate & 102 & 60 & $\begin{array}{l}0.71(0.44, \\
1.17)\end{array}$ & $\begin{array}{l}1.04(0.59 \\
1.82)\end{array}$ \\
\hline \multicolumn{5}{|l|}{ Residence } \\
\hline Rural & 578 & 412 & 1 & 1 \\
\hline Urban & 144 & 132 & $\begin{array}{l}1.29(0.89 \\
1.89)\end{array}$ & $\begin{array}{l}1.52(1.10 \\
2.22)\end{array}$ \\
\hline
\end{tabular}

\section{Discussion}

A study on "the knowledge, attitude, and predictors of safe abortion among female students is important to reduce the burden associated with unsafe abortion. The study found that knowledge of safe abortion 
among students was $68.5 \%$ (95\% Cl: $64.9,72.5)$. The finding is in agreement with $72.5 \%$ reported in a study conducted in Nigeria (24). The finding is also supported by a finding reported in Ethiopia (15) though higher than findings reported by a study in India $44.2 \%$ (7). The variance in the findings can be attributed to the fact that this study compared to the study in India conducted among diploma students, this study was conducted among bachelors' degree students. Bachelor degree students have intense academic programmes with wide range of technical and theoretical knowledge of subjects, and as a result, students tend to have better knowledge in many health issues compared to diploma students. This view is supported by a study in India that found that the increase in students' year of study also increased students' level of knowledge (7). The variance in findings can also be explained in relation to differences in the level of access to health information because this study was conducted among students in universities located in urban areas compared to studies in India conducted among students in rural universities highlighting the digital divide or gap between individual students, their families, and geographic areas and different socio-economic levels with regard to both students' opportunities to access information and communication technologies and to their use of the Internet to acquire knowledge" on safe abortion.

Students "aged 25 and above were 2.79 more likely to have adequate knowledge of safe abortion than students aged between 18 and 19 years. The finding can be attributed to the view reported in a study in Nigeria that found an association between students' increase in age and exposure to information increase (24). In agreement, a study in South Africa and a study in Zambia found that increase in age was associated with heavy internet exposure making students to consume uncensored knowledge including knowledge" on safe abortion $(4,14)$.

Students from "urban areas reported to be more knowledgeable than students from rural areas. The finding does not come as a surprise because a study in South Africa and a study in Ethiopia found that students from urban areas had easy access to information and educational material because of access to sources including the Internet, newspapers, journals, transcripts from radio or television programmes, leaflets, photographs and other artefacts not readily accessible to students living in rural areas $(9,10)$. The finding implies that there is gap between the information haves and have-nots. The study in Nigeria reinforces this finding as it found that 'digital divide' or the gap between students from urban areas who have access to digital technologies and information on the Internet, and students from rural areas who do not have influenced students' level of knowledge of safe abortions (24). A study in Kenya supports this view as it reported that poverty, illiteracy, lack of infrastructure, and inadequate government interest and intervention have led to the information have-not situation in rural areas denying students from rural areas knowledge on many issues including" safe abortions (15).

The study "found that students with both parents who were literate were more than three times likely to have good knowledge of safe abortion than students with parents who were both illiterate. The finding is in agreement with a study conducted in India and Argentina $(7,11)$. The finding is attributed to the view that students with both parents who are literate or have a higher level of formal education let their children know additional things about safe abortion. In agreement, a study in Ethiopia found that 
students with educated parents were more knowledgeable than their counterparts because facts, information and skills gained through parents' own experiences or learnings made it easy for parents to share information with their children on health matters including" safe abortion (10).

The study "revealed that students who had heard about safe abortion were more likely to have good knowledge than their counterparts. The finding is supported by a study conducted in Ethiopia that reported similar results (10). The explanation to this finding is that the media provides students with information on safe abortion that increases students' knowledge on safe abortion while a study in South Africa found that youths' access to youth friendly sexual and reproductive health services or clinics that deliver a comprehensive range of sexual and reproductive health services in ways that are responsive to the specific needs, vulnerabilities and desires of young people increased their knowledge of safe" abortions (18).

The study "indicated that $58 \%(95 \% \mathrm{Cl}: 52.7,60.9)$ of students had a positive attitude towards safe abortion. The finding is in agreement with a study conducted in the United States that reported similar results (23). However, the finding in this study is higher than findings in a study conducted in Somalia (40.9\%) (19). The difference in findings may be because of diverse cultural beliefs where South Africa is more a secular state that allows diverse lifestyles and legalised safe abortion practices a long time ago while Somalia is religiously conservative country to have just recently allowed safe" abortion.

Students "aged 25 and above were 6.58 times more likely to have a positive attitude towards safe abortion than students aged between 18 and 19. The finding is supported by a study conducted in India that reported similar results (7). The reason for this finding can be attributed to the perspective that as students' age increases, their familiarity or awareness of facts about abortion also increases making them more knowledgeable than younger students. Besides, it is possible that most of the students aged 25 and above are in their senior level of study therefore increasing their level of awareness and knowledge than those aged between 18 and 19 who are mostly in their junior level" of study.

\section{Conclusion}

The study "found that more than one third of the students had good knowledge while half had a favourable attitude towards safe abortion. However, a significant number of students had poor knowledge and unfavourable attitude towards safe abortion. Findings show that having ever heard about abortion, residence, age of students, and family education were predictors of knowledge on safe abortion. In addition, age and residents were predictors of students' attitude towards abortion. There is need for health communication and education programmes to address the subject of safe abortion among students. Health communication and education programmes should target students from rural areas and employ age-specific health communication programmes. There is need for government to provide youthfriendly reproductive services to the rural areas" of South Africa.

\section{Availability of data and materials}

Page $17 / 21$ 
The datasets used and/or analysed during this study are available from the corresponding author on reasonable request.

\section{Abbreviations}

SPSS: Statistical Package for the Social Sciences

WHO: World Health Organization

\section{Declarations}

\section{Acknowledgments}

The author would like to thank students in public universities in Eastern Cape who completed the survey. I would also like to acknowledge all the people who have spoken out around the world about safe abortion.

\section{Declaration of conflicting Interests}

The author declared no potential conflicts of interest with respect to the research, authorship, and/or publication of this article.

\section{Funding}

The author received no financial support for the research, authorship, and/or publication of this article.

\section{Authors' contributions}

The author conceptualised the study, designed data collection tools, and wrote the first draft of the manuscript including designing the tables used to summarise data.

\section{Author information}

1. Given Mutinta sole author, Senior Lecturer

\section{Affiliation}

Nelson Mandela University, Media and Communication, Summerstrand, South Campus

\section{Corresponding author}

Given Mutinta, Email: Chigaya24@gmail.com

\section{Ethics declarations}

Ethical clearance was obtained from the Research Ethics Committee at Nelson Mandela University. The four universities under study provided gatekeepers' letters. Consent forms were signed by all participants. 
Students were informed that participation in the study was voluntary and were at liberty to withdraw from the study anytime without any consequences. Confidentiality, privacy, and anonymity were upheld. Complete information regarding the ethical clearance reference number was available in the research report. All methods used in the research project were carried out in accordance with relevant guidelines and regulations.

\section{Consent for publication}

Not applicable.

\section{Competing interests}

The author declares that they have no competing interests.

\section{References}

1. Harries J, Constant D. Providing safe abortion services: experiences and perspectives of providers in South Africa. Best Pract Res Clin Obstet Gynaecol. 2020, 62:79-89. Article PubMed Google Scholar

2. Favier M, Greenberg JMS, Stevens M. Safe abortion in South Africa: "We have wonderful laws but we don't have people to implement those laws." Int J Gynaecol Obstet. 2018, 143(4):38-44. Article PubMed Google Scholar

3. Harries J, Cooper D, Strebel A, Colvin CJ. Conscientious objection and its impact on abortion service provision in South Africa: a qualitative study. BMC Reproductive Health. 2014, 11(1):16. Article Google Scholar

4. Park, YS, Konge L, Artino T. The Positivism Paradigm of Research. Academic Medicine. 2020, 95, 690-694. Article Google Scholar

5. Harrison A, Montgomery ET, Lurie M, Wilkinson D. Barriers to implementing South Africa's termination of pregnancy act in rural KwaZulu/Natal. Health Policy Plan. 2000, 15:424-31. CAS Article Google Scholar

6. Jewkes RK, Gumede T, Westaway MS, Dickson K, Brown H, Rees H. Why are women still aborting outside designated facilities in metropolitan South Africa? BJOG An Int J Obstet Gynaecol. 2005,112 (9):1236-42. Article Google Scholar

7. Palo LB, Chauhan NS, Parvathi T, Chauhan RC. Awareness regarding abortions and medical termination of pregnancy act among medical students in Puducherry, India. International Journal of Research in Medical Sciences. 2017, 3(10): 2729-2733. Publisher Site|Google Scholar

8. Harries J, Momberg M, Gerdts C, Greene FD. An exploratory study of what happens to women who are denied abortions in a legal setting in South Africa. BMC Reprod Health. 2015, 12:21. Article 
Google Scholar

9. Constant D, Grossman D, Lince N, Harries J. Self- induction of abortion among women accessing second trimester abortion services in the public sector, Western Cape, South Africa: an exploratory study. South Afr Med J. 2014, 104(4):302-5. CAS Article Google Scholar

10. Dereje RYDA, Meleko A.Knowledge, attitude and practice towards induced abortion and associated factors among female students in Yebu secondary school, jimma zone, south west Ethiopia. Global Journal of Reproductive Medicine. 2018, 5 (2). Publisher Site | Google Scholar

11. Brodahl A, Hovind MJ. Knowledge and attitudes towards abortion among the first year medical students, University of Buenos Aires, Argentina. 2012, M.Sc. thesis. Google Scholar

12. Bernard HR: Research methods in anthropology: Qualitative and quantitative approaches. 2nd ed. Newbury Park: Sage Publications; 1994. Google Scholar

13. Moseson H, Herold S, Filippa S, Barr-Walker J, Baum SE, Gerdts C. Self-managed abortion: a systematic scoping review. Best Pract Res Clin Obstet Gynaecol. 2020, 63:87-110. Article Google Scholar

14. Coast E, Murray SF.These things are dangerous: Understanding induced abortion trajectories in urban Zambia. Soc Sci Med. 2016, 153:201. Article Google Scholar

15. Izugbara CO, Egesa C, Okelo R. High profile health facilities can add to your trouble: women, stigma and un/safe abortion in Kenya. Soc Sci Med. 2015, 141:9-18. Article Google Scholar

16. Gelaye AA, Taye KN, Mekonen T. Magnitude and risk factors of abortion among regular female students in wolaita sodo university, Ethiopia. BMC Women's Health. 2014, 14(1): 50. Publisher Site I Google Scholar

17. Raifman S, Ralph L, Biggs MA, Grossman D. "I'll just deal with this on my own”: a qualitative exploration of experiences with self-managed abortion in the United States. Reprod Health. 2021, 18(1):91. Article Google Scholar

18. Steenkamp V. Traditional herbal remedies used by South African women for gynaecological complaints. J Ethnopharmacol. 2003;86(1):97-108. CAS Article PubMed Google Scholar

19. Moseson H, Jayaweera R, Raifman S, Keefe-Oates B, Filippa S, Motana R. Self-managed medication abortion outcomes: results from a prospective pilot study. Reprod Health. 2020, 17(1):164. Article Google Scholar

20. Rodgers YVM, Coast E, Lattof SR, Poss C, Moore B. The macroeconomics of abortion: A scoping review and analysis of the costs and outcomes. PLoS One. 2021, 16(5). PMCID: PMC8101771 
21. Neuman, WL.Basics of Social Research, 3rd Ed. Boston: Pearson/Allyn and Bacon. 2012.

22. Mirembe F, Karanja J, Hassan E0, Faúndes A. Goals and activities proposed by countries in seven regions of the world toward prevention of unsafe abortion. International Journal of Gynaecology \& Obstetrics. 2010, 110 (Suppl) S25-S29.

23. Grossman D, Holt K, Peña M, Lara D, Veatch M, Córdova D. Self-induction of abortion among women in the United States. Reprod Health Matters. 2010, 18(36):136-46. Article Google Scholar

24. Cadmus EO, Owoaje ET. Knowledge about complications and practice of abortion Among female undergraduates in the university of Ibadan, Nigeria. Annals of Ibadan Postgraduate Medicine. 2011, 9(1):19-23. Publisher Site | Google Scholar

25. Gerdts C, Raifman S, Daskilewicz K, Momberg M, Roberts S, Harries J. Women's experiences seeking informal sector abortion services in Cape Town, South Africa: a descriptive study. BMC Womens Health. 2017, 17(1):1-10. Article Google Scholar

26. Coast E, Lattof SR, Meulen Rodgers YV, Moore B, Poss C. The microeconomics of abortion: A scoping review and analysis of the economic consequences for abortion care-seekers. PLoS One. 2021, 9 (16:e0252005. PMCID: PMC8189560.

27. Lattof SR, Coast E, Rodgers YVM, Moore B, Poss C. The mesoeconomics of abortion: A scoping review and analysis of the economic effects of abortion on health systems. PLoS One. 2020, 4; 15(11):e0237227. Google Scholar 